\title{
Inter-technique agreement between two- dimensional echocardiography and cardiovascular magnetic resonance imaging in the setting of bicuspid aortic valve disease
}

Beatriz Miralles Vicedo, Liying Cai*, Karima Addetia, Francesco Maffessanti, Kirk T Spencer, Roberto Lang, Victor Mor-Avi, Amit R Patel

From 17th Annual SCMR Scientific Sessions

New Orleans, LA, USA. 16-19 January 2014

\section{Background}

Bicuspid aortic valve (BAV) is the most common form of congenital heart disease and $30-50 \%$ of BAV have an associated aortopathy. Accurate aortic measurements are therefore particularly important in these patients. Two-dimensional echocardiography (2DE) is typically used to follow the aortic size in these patients; however, cardiovascular magnetic resonance (CMR) offers the potential advantage of 3-dimensional datasets that can be used to make more accurate measurements. Intertechnique differences in aortic measurements for BAV patients using these techniques has not been extensively studied. Our aim was to evaluate the measurement variability associated with each technique and their mutual agreement in measuring the aortic root.

\section{Methods}

Retrospective review of patients with BAV who had both CMR and 2DE. Contrast-enhanced magnetic resonance angiography (MRA) or 3D whole-heart imaging (Philips 1.5-T scanner) combined with offline analysis with double oblique planes were used to obtain measurements of the sinus of Valsalva (SOV) on CMR (dimension 1 and 2). On $2 \mathrm{DE}$, the SOV was measured on the parasternal long axis view using the inner-edge to inner-edge technique. Bland-Altman analysis was performed to evaluate the inter-technique agreement between 2DE and CMR. Intraobserver reproducibility was measured as coefficient of variation (CV) and 95\% confidence intervals between repeated measurements.

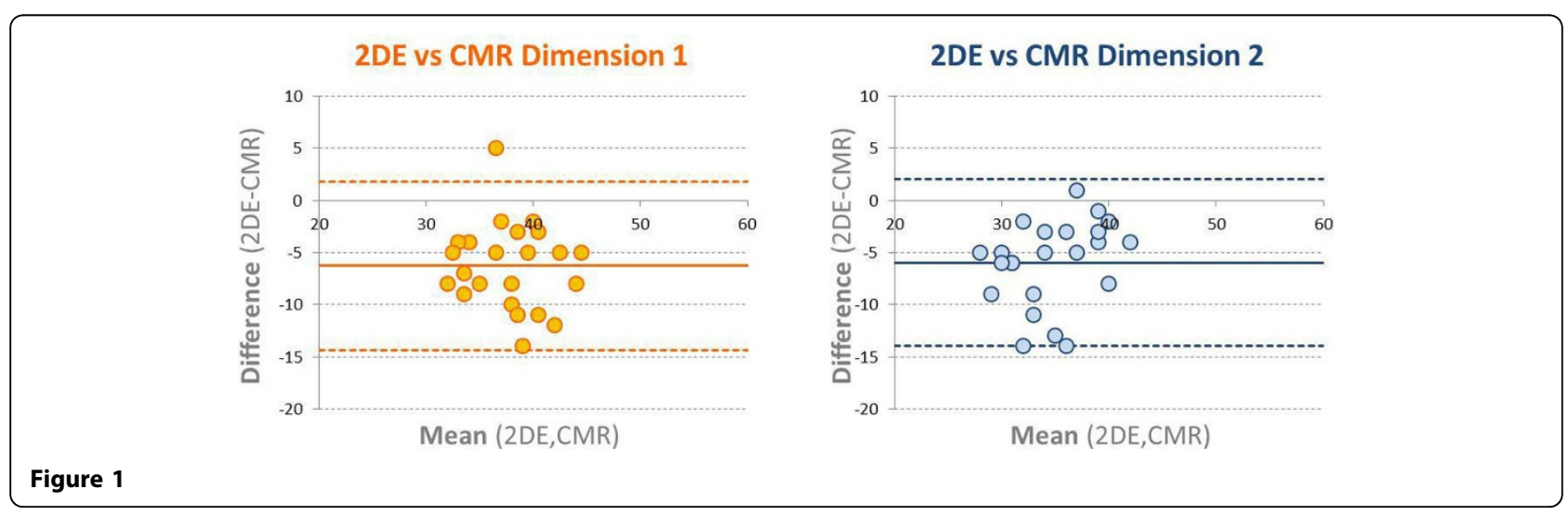

Cardiology, University of Chicago, Chicago, Illinois, USA 


\section{Results}

Twenty-three patients (age $40 \pm 13$ years; range 23-65; 22 men) were studied. The average SOV measurement on $2 \mathrm{DE}$ was $35 \pm 4 \mathrm{~mm}$, and $41 \pm 4 \times 41 \pm 5 \mathrm{~mm}$ on CMR. Correlation between maximal 2DE and CMR diameters was moderate $(r=0.69)$; Bland-Altman analysis showed significant underestimation by $2 \mathrm{DE}$ when compared to CMR dimension 1 (bias $=-6.3 \mathrm{~mm}, \mathrm{LOA}=$ [-14.3-1.8]) and dimension 2 (bias $=-6.0 \mathrm{~mm}, \mathrm{LOA}=$ [-14.0-2.1]) (Figure 1). Both 2DE and CMR were highly reproducible in terms of CV (3.2 and 3.4\%, respectively) with narrower confidence interval for CMR $( \pm 2.1 \mathrm{~mm})$ than for $2 \mathrm{DE}( \pm 4.8 \mathrm{~mm})$.

\section{Conclusions}

2DE measurements are more variable and significantly underestimate SOV dimensions compared to CMR in patients with BAV. If serial $2 \mathrm{DE}$ is being considered to follow aortic root dimensions, CMR should be performed to confirm that the measurement is not significantly underestimating the true maximum diameter.

\section{Funding}

None.

Published: 16 January 2014

doi:10.1186/1532-429X-16-S1-P129

Cite this article as: Vicedo et al:: Inter-technique agreement between two-dimensional echocardiography and cardiovascular magnetic resonance imaging in the setting of bicuspid aortic valve disease. Journal of Cardiovascular Magnetic Resonance 2014 16(Suppl 1):P129.

Submit your next manuscript to BioMed Central and take full advantage of:

- Convenient online submission

- Thorough peer review

- No space constraints or color figure charges

- Immediate publication on acceptance

- Inclusion in PubMed, CAS, Scopus and Google Scholar

- Research which is freely available for redistribution

Submit your manuscript at www.biomedcentral.com/submit 